\title{
Synthesis, structure and reactivity of oxalyl di(4-methylimidazole)
}

\author{
C Pyotr P. Purygin, ${ }^{1}{ }^{+}$Alina V. Shargalo, ${ }^{1}$ Konstantin V. Milyutin, ${ }^{1}$ \\ Olga B. Grigoryeva, ${ }^{2}$ and Yury P. Zarubin ${ }^{1}$ \\ ${ }^{1}$ Chair of Inorganic Chemistry. Samara National Research University. Moskovskoe Ave., 34. Samara, \\ 443086. Samara Region.Russia.Phone: +7 (846) 334-54-59.E-mail:puryginpp2002@mail.ru \\ ${ }^{2}$ Department of Chemistry, Chemical Processes and Technologies. Togliatti State University. \\ Belorusskaya St., 14a. Togliatti, 445020. Samara Region. Russia. \\ Phone:+7 (903)330-17-14.E-mail: groly@yandex.ru
}

*Supervising author; ${ }^{+}$Corresponding author

Keywords: oxalyl di(4-methylimidazole), synthesis, hydrolysis, alcoholysis, aminolysis, kinetics, rate constant, half-life, calculations, thermodynamic characteristics, quantum-chemical, molecular mechanical, biological activity, prediction.

\begin{abstract}
The article describes a two-step method for the synthesis of oxalyl di(4-methylimidazole) from 4(5)methylimidazole through 1-trimethyl-4-methylimidazole followed by interaction with oxalyl chloride; the yield of the final product is $89 \%$. The kinetics of hydrolysis, alcoholysis, and aminolysis of oxalyl di(4methylimidazole) in acetonitrile - water $(9: 1)$, acetonitrile - methanol $(9: 1)$, acetonitrile - diethylamine $(9: 1)$ at $25^{\circ} \mathrm{C}$ was studied. To study the thermodynamic features of the reactions to obtain this compound in the Spartan'14 1.1.4 program, a number of thermodynamic characteristics were determined that determine the spontaneous and exothermic nature of the process. The data obtained make it possible to select the optimal conditions for the synthesis of oxalyl di(4-methylimidazole) and to draw a conclusion about its low stability in media containing nucleophiles.

Possible conformers were found for the oxalyl di(4-methylimidazole) molecule in the Molecular Operating Environment 2014.0901 program, for which nucleophilic susceptibility surfaces were calculated in the SCIGRESS Modeling 3.1.4 program. It was shown that the most reactive conformers in which carbonyl groups are minimally screened by fragments of 4-methylimidazole.

The structure of oxalyl di(4-methylimidazole) was confirmed by IR and ${ }^{1} \mathrm{H}$ NMR spectroscopy. Characteristic absorption bands were found in the IR spectra, confirming the presence of the corresponding functional groups in the structure of the compound, and proton signals with characteristic chemical shifts for the corresponding functional groups were detected in ${ }^{1} \mathrm{H}$ NMR spectra. In the PASS Professional 2007 program, the most probable types of biological activity of the test compound were predicted. The most significant types of biological activity are in relation to urological diseases, antiseborrheic effect, stimulator of renal function, stimulator of leukopoiesis.
\end{abstract}

\section{References}

[1] V.A. Kataev. Thietanes based on benzimidazole and imidazole. Synthesis, structure and biological properties. 2006. 46p. (russian)

[2] G.N. Freidlin. Aliphatic dicarboxylic acids. Moscow: Khimiya. 1978. Vol.16. 263p. (russian)

[3] G. Singh, K. Chowdhary, P. Satija, A. Singh, B. Singh, K. Singh, C. Espinosa, M.A. Esteban, R. Sehgal, V. Verma. Biological Chemistry and Chemical Biology. 2018. No.3. P.1609-1614.

[4] A-R. Farghaly, H. El-Kashef. General Papers. 2006. No.6. P.76-90.

[5] https://www.chemicalbook.com/ProductChemicalPropertiesCB9400519_EN.htm 